\title{
Long-term efficacy of primary laser trabeculoplasty
}

.T Elsås, $\mathrm{H}$ Johnsen

\begin{abstract}
Sixty glaucomatous eyes of 60 patients treated with laser trabeculoplasty as primary therapy were reviewed retrospectively. There were 42 eyes with capsular glaucoma and 18 with simple glaucoma. The mean prelaser intraocular pressure (IOP) was 35.2 (SD= 6.5) $\mathrm{mmHg}$. Success was defined as IOP $\leqslant 22$ mmHg without medication. The probability of success was 0.73 at 1 year, 0.66 at 2 years, 0.57 at 3 years, and 0.50 at 4 years. Three eyes experienced progressive visual field loss or disc damage in spite of an intraocular pressure below $22 \mathrm{mmHg}$ without medication. High prelaser pressure and the severity of the visual field defects were significant predictors of treatment failure.
\end{abstract}

Laser trabeculoplasty (LTP) was introduced as an alternative to filtering surgery in the presurgical glaucoma patient on full medication. ${ }^{1}$ Several reports have noted the efficacy and low complication rate associated with this procedure. ${ }^{1-3}$ There are now a number of studies of it as a primary treatment in glaucoma. ${ }^{49}$ The first results of a multicentre controlled study have recently been published. ${ }^{10}$ To the best of our knowledge there are only two reports on long term results with primary LTP. ${ }^{89}$

We have retrospectively studied the long term results with laser as primary treatment in 60 eyes of 60 patients.

\section{Material and methods}

The patients were collected from two earlier prospective studies on primary LTP investigating $180^{\circ}$ versus $360^{\circ}$ treatment ${ }^{\prime \prime}$ and the immediate pressure response to one- and twostage LTP. ${ }^{12}$ In these two studies 66 eyes were treated in 60 patients. For six patients one eye was randomised for one-stage and the other for two-stage treatment. One eye from each of these patients was randomised to the present study. There were 25 women and 35 men in the study sample. The mean age was $71 \cdot 5(\mathrm{SD}=9 \cdot 2)$ years. The material consisted of 18 eyes with simple glaucoma and 42 with capsular glaucoma.

The patients had to meet all of the following

University of Trondheim, Norway

Department of

Ophthalmology

T Elsås

Department of Clinical Chemistry

H Johnsen

Correspondence to: Tor Elsås, MD, Departmen of Ophthalmology, University of Trondheim, N-7006 Trondheim, Norway. Accepted for publication 2 August 1990
The cupping and pallor of the disc were evaluated with a Goldmann contact lens according to Schwartz. ${ }^{13}$ Fundus photography was not performed. Glaucomatous damage of the optic nerve head was defined as a vertical cupdisc ratio $\geq 0.5$ and at least one of the following criteria: (a) cupping of the optic nerve head extending to the margin of the disc; (b) a difference of 0.2 or more of the $C / D$ ratio between the two eyes; $(c)$ different degrees of disc pallor in the two eyes with no other explanation subjectively assessed by one of the authors (TE) by contact lens examination.

Progressive disc damage was judged to have occurred with an increase in the C/D ratio of 0.2 or more and/or cupping progressing to the disc margin. Disc changes were subjectively estimated by one of the authors (TE) by contact lens examination comparing the present findings with the written description and drawings from the entry of the patients into the two earlier prospective LTP studies, 112 using the recommendations of Schwartz. ${ }^{13}$ The optic nerve head was in these two studies evaluated by the same person (TE).

The visual field was examined with the Humphrey Visual Field Analyzer using the suprathreshold Armaly full field screening test ${ }^{11}$ or the suprathreshold 76-point central screening test. ${ }^{12}$ Both programs apply a quantified defect strategy. The original study" started some months before our automated perimetry service was established, and during this period the visual fields were plotted by Goldmann perimetry. In addition Goldmann perimetry was performed in patients who did not co-operate during automated perimetry or who had extensive central field defects. Glaucomatous visual field defects were defined as having at least three contiguous spots within the central $30^{\circ}$ field and a depth of $\geq 5 \mathrm{~dB}$. We used the criteria of Ticho and Nesher ${ }^{3}$ for detecting visual field decay in eyes monitored by automated perimetry and the criteria of Kidd and $\mathrm{O}^{\prime}$ Connor ${ }^{14}$ in patients followed up by Goldmann perimetry. Visual field deterioration was confirmed by retesting. Visual field defects were given scores according to the following classification.

0: Normal.

1: Scattered defects with a depth of $\geq 5 \mathrm{~dB}$ not creating a complete Bjerrum scotoma.

2: Spots with a depth $\geq 5 \mathrm{~dB}$ creating a complete Bjerrum scotoma extending from the blind spot to the horizontal nasal meridian.

3: Larger defects than 2.

Goldmann defects were classified according to Aulhorn. ${ }^{15}$ The pigmentation of the chamber angle was not evaluated.

All patients were scheduled for re-examination by one of the authors and had the same ophthalmic examination as in the two reports ${ }^{11} 12$ which recruited the patients to our study. Four patients died during the observation period and one patient did not attend for examination. The files of these patients were checked for the information needed, and it was included in the material up to their last visit. 
Success was defined as IOP $\leq 22 \mathrm{mmHg}$ without medication. When the patient did not meet those criteria the result was classified as failure. If the IOP exceeded $22 \mathrm{mmHg}$, topical medication was added. If this was not sufficient, the patient was referred for trabeculectomy. During the first two weeks after laser treatment higher pressure levels were allowed before starting medication. If the intraocular pressure was $\geq 40 \mathrm{mmHg}$ the day after LTP,$\geq 30 \mathrm{mmHg}$ after one week, or $\geq 25 \mathrm{~mm}$ after two weeks, medication was prescribed.

LTP was performed with a Coherent argon laser photocoagulator. The spots were placed just in front of the scleral spur, with blanching, bubble formation, and pigment dispersion as the criteria for adequate laser exposure. Application parameters were $50 \mu \mathrm{m}$ spot size, 0.1 second duration, and a mean power of $1.2 \mathrm{~W}$ (range $0 \cdot 8$ $2 \cdot 0$ ). The treatment was performed by one of the authors to keep the technique unchanged during our two studies. One hundred spots were distributed in $360^{\circ}$ except for 14 eyes randomised to two sessions of 50 spots in $180^{\circ}$ with an interval of four weeks.

Since the purpose of the present work is to relate the outcome of primary LTP to elapsed time and certain characteristics of the subjects under study (age, type of glaucoma, pretreatment IOP, etc), lifetime data analysis (survival analysis) expressing the characteristics as concomitant variables in a regression model is appropriate. ${ }^{16}$

The probability of success (survivor function) is estimated by the Kaplan-Meier method. ${ }^{17} \mathrm{~A}$ hazard plot is shown to indicate the failure rate pattern, and the empirical failure rate is also estimated. The predictors of failure are evaluated by the Cox regression model ${ }^{18}$ using a stepwise procedure as implemented in the Survival module in the SYSTAT statistical package. ${ }^{19}$ Model control is carried out by residual analysis and graphical methods.

\section{Results}

Prelaser variables are listed in Table 1.

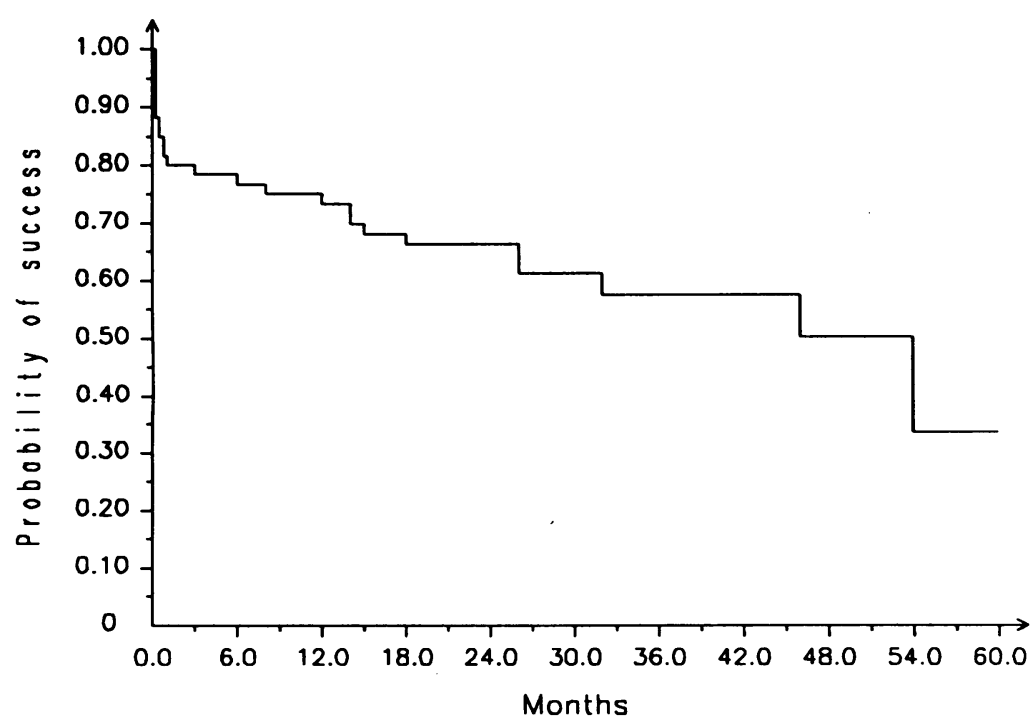

Figure 1 Kaplan-Meier plot showing probability of success for glaucomatous patients treated with primary LTP.
Table 1 Prelaser variables in eyes treated with primary LTP

\begin{tabular}{ll}
\hline Mean age & $71 \cdot 5(\mathrm{SD}=9 \cdot 2)$ years \\
Mean prelaser IOP & $35 \cdot 2(\mathrm{SD}=6 \cdot 5) \mathrm{mmHg}$ \\
$\begin{array}{l}\text { Mean cup-disc ratio } \\
\text { Number of eyes (\%) with cupping }\end{array}$ & $0 \cdot 72(\mathrm{SD}=0 \cdot 16)$ \\
$\begin{array}{l}\text { extending to the margin of the disc } \\
\text { Mean visual field defects score in eyes }\end{array}$ & $26(43 \%)$ \\
examined with automated perimetry & $1 \cdot 5(\mathrm{SD}=1 \cdot 4)$ \\
\hline
\end{tabular}

The total number of observations was 60,23 of which were observed to fail. The Kaplan-Meier plot in Fig 1 shows the unconditional probability of success as a function of time since treatment. Accordingly, the probability of success was 0.73 at 1 year, 0.66 at 2 years, 0.57 at 3 years, and 0.50 at 4 years.

The hazard plot (Fig 2) indicates a rapidly decreasing failure rate during the first month after treatment, presumably because of failure in non-responders. The failure rate flattened out to a reasonably stable level, and increased towards the end of the observation period as seen in Fig 3. Twelve of a total of 23 failures occurred during the first month after LTP.

The high initial failure rate had a marked effect on the probability of success in the whole material. It is therefore worthwhile assessing the probability of success given success at 1 month. These probabilities were as follows: 0.92 at 1 year, 0.83 at 2 years, 0.72 at 3 years, and 0.63 at 4 years. Of the observed 23 eyes which failed, 18 needed medication on account of high pressure, and five were referred to trabeculectomy because of high IOP. Mean postlaser pressure in successfully treated eyes on the last visit was $15 \cdot 6(\mathrm{SD}=$ 2.6) $\mathrm{mmHg}$.

We used only the pressure response as a criterion of success, while many other studies have also included stable visual field and optic disc in the definition of successful treatment. In our series two patients experienced deteriorating visual fields and one progressive cupping of the optic nerve head in spite of normal intraocular pressure without medication.

None of the other studies on primary LTP evaluated their results by lifetime data analysis as recommended by Gaasterland. ${ }^{20}$ To make our results comparable with these reports we also included all patients, both successes and failures, up to the date of their last clinical visit. The mean follow-up of the material when evaluated in this manner was $34(\mathrm{SD}=13)$ months. Our results are compared with those of other studies in Table 2 .

High prelaser IOP and visual field defect score were predictors of treatment failure $(p<0.05)$. Table 3 presents the success rate at different levels of prelaser IOP. Age, sex, capsular or simple glaucoma, $180^{\circ} \times 2$ versus $360^{\circ}$ treatment, laser power, or the cup-disc ratio did not influence the outcome of treatment significantly.

The rate of complications and postlaser pressure elevations have been recorded elsewhere. 112

\section{Discussion}

Our results are compared with those of other reports on primary LTP in Table 2 . None of these studies have evaluated their results by lifetime data analysis. These investigations differ 


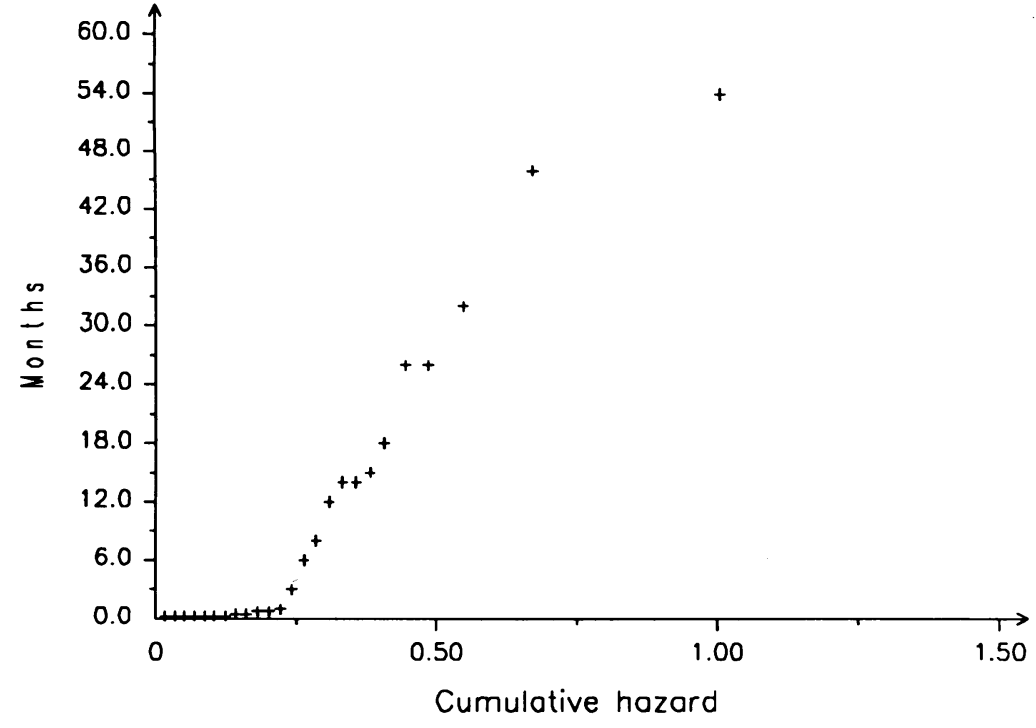

Figure 2 Plot of cumulative hazard with time since treatment with primary LTP. The curve indicates an initially decreasing failure rate and an increasing failure rate towards the end of the observation period.
Table 3 Prelaser IOP related to the success rate in primary LTP

\begin{tabular}{ll}
\hline $\begin{array}{c}\text { Prelaser IOP } \\
\mathrm{mmHg}\end{array}$ & $\begin{array}{c}\text { Success rate: number of successful eyes/ } \\
\text { total number of eyes }(\%) \\
\geq 40\end{array}$ \\
$<4 / 12(33 \%)$ \\
$\geq 30$ & $26 / 37(70 \%)$ \\
$<30$ & $7 / 11(64 \%)$ \\
$\geq 25$ & \\
\hline
\end{tabular}

The longterm studies of Tuulonen $e t a l^{9}$ and Migdal and Hitchings ${ }^{8}$ are not directly comparable to ours. The material of Tuulonen et al contains only cases of early glaucoma with a considerably lower prelaser pressure than in our study. They reported that $50 \%$ were successfully treated after five years. Migdal and Hitchings's cases consisted exclusively of simple glaucoma, while our study has a majority of capsular glaucoma. Their prelaser IOP of $34.9 \mathrm{mmHg}$ was comparable with ours. In their material $44 \%$ were successfully treated after a follow-up period varying between seven months and three years. After four years $50 \%$ were successful in our study.

The failure rate pattern indicates that the first month after treatment is critical in the sense that the majority of eyes which are susceptible to

Table 2 Six studies on primary LTP compared with the present report

\begin{tabular}{|c|c|c|c|c|c|}
\hline & $\begin{array}{l}\text { Follow-up } \\
\text { (months) }\end{array}$ & Number of eyes & $\begin{array}{l}\text { Type of } \\
\text { glaucoma }\end{array}$ & Prelaser IOP $(\mathrm{mmHg})$ & Success rate $(\%)$ \\
\hline Tuulonen $e t a l^{6}$ & $\begin{array}{l}12 \\
18 \\
12 \\
18\end{array}$ & $\begin{array}{l}21 \\
18 \\
42 \\
34\end{array}$ & $\begin{array}{l}\text { Glaucoma } \\
\text { simplex } \\
\text { Glaucoma } \\
\text { capsulare }\end{array}$ & $\begin{array}{l}25 \cdot 6(\mathrm{SD}=0 \cdot 9) \\
25 \cdot 1(\mathrm{SD}=0 \cdot 7) \\
27 \cdot 0(\mathrm{SD}=0 \cdot 7) \\
27 \cdot 3(\mathrm{SD}=0 \cdot 7)\end{array}$ & $\begin{array}{r}81 \\
78 \\
100 \\
94\end{array}$ \\
\hline Thomas et als & $3-10$ & 30 & $\begin{array}{l}\text { Mostly glaucoma } \\
\text { simplex }\end{array}$ & $30 \cdot 3$ & 83 \\
\hline Rosenthal et $a l^{4}$ & $6-18 \cdot 5$ & 43 & $\begin{array}{l}\text { Glaucoma } \\
\text { simplex }\end{array}$ & $\begin{array}{l}\text { Among successes } \\
\text { First eye treated } 30 \cdot 7(\mathrm{SD}=1 \cdot 3) \\
\text { Second eye treated } 29 \cdot 7(\mathrm{SD}=1 \cdot 9) \\
\text { Among failures } 34 \cdot 1(\mathrm{SD}=2 \cdot 0)\end{array}$ & 65 \\
\hline Tuulonen et al & 12 & 19 & $\begin{array}{l}\text { Glaucoma } \\
\text { capsulare and } \\
\text { simplex }\end{array}$ & $29 \cdot 4(\mathrm{SD}=7 \cdot 6)$ & 53 \\
\hline $\begin{array}{l}\text { Migdal and Hitchings }{ }^{8} \\
\text { Tuulonen et al }\end{array}$ & $\begin{array}{l}7-36 \\
60\end{array}$ & $\begin{array}{l}57 \\
32\end{array}$ & $\begin{array}{l}\text { Glaucoma simplex } \\
\text { Glaucoma simplex } \\
\text { Glaucoma capsulare }\end{array}$ & $\begin{array}{l}34 \cdot 9 \\
24 \cdot 0(S D=3 \cdot 1) \\
26 \cdot 4(S D=3 \cdot 7)\end{array}$ & $\begin{array}{l}44 \\
50\end{array}$ \\
\hline Present study & $\begin{array}{l}12 \\
24 \\
36 \\
48\end{array}$ & $\begin{array}{l}60 \\
50 \\
25 \\
12\end{array}$ & $\begin{array}{l}\text { Glaucoma } \\
\text { capsulare and } \\
\text { simplex }\end{array}$ & $35 \cdot 2(\mathrm{SD}=6 \cdot 5)$ & $\begin{array}{l}76 \\
64 \\
52 \\
50\end{array}$ \\
\hline
\end{tabular}

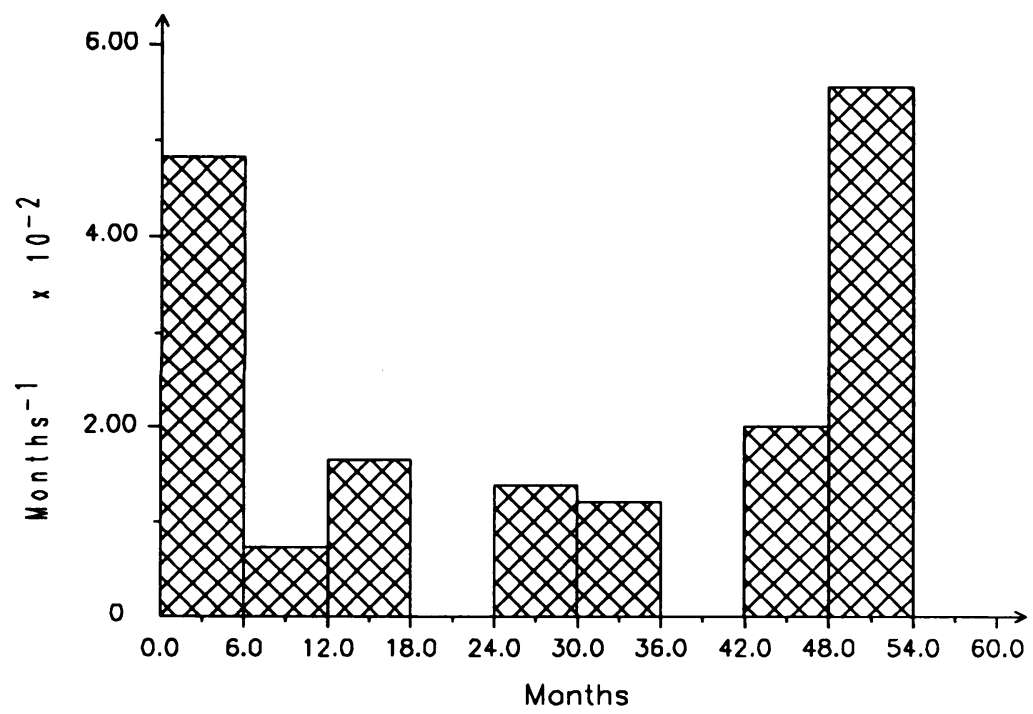

Figure 3 Estimated failure rate in time intervals after primary LTP. failure in the first year will fail during the first month, and success beyond one month considerably increases the probability of long lasting success. Our observations show, however, that the failure rate increases after four years of success. So, although the data are sparse, they suggest an increasing failure probability after a rather stable level from one month to about four years after treatment. Shingleton et al, ${ }^{21}$ studying patients with glaucoma on medication, noted a failure rate of $23 \%$ during the first year after LTP, which then levelled off to about $10 \%$ per year.

Only Rosenthal et $a l^{4}$ have analysed prognostic factors in primary LTP. They observed, as in our study, that high pretreatment intraocular pressure was associated with treatment failure. The degree of glaucomatous damage, in contradiction to our results, did not influence the 
results of LTP in their material. They also noted that well delineated angle landmarks were a predictor of success. The date of treatment was also correlated with successful treatment. Of the first 15 patients four were successes, while 14 of the final 18 patients were successes. This fact was interpreted as increased success when gaining experience with the procedure. All the eyes in our material were treated by the same experienced laser surgeon. We did not relate chamber angle parameters to treatment results.

There are several studies of the effect of different prelaser variables on the outcome of LTP in glaucoma patients on medication..$^{1-321-29}$

These studies differ regarding the factors influencing the result of treatment. Possible explanations of their contradictory results are that some of the series were too small, some authors did not apply lifetime data analysis, some series contained different types of glaucoma, and different criteria for success were adopted; moreover the values of some parameters were clustered round a median value and did not extend over a wider range. Age A22 $2526^{26}$ and capsular glaucoma ${ }^{232428}$ are the factors most consistently related to the outcome of treatment by other authors. Schwartz et $a l^{2}$ and Tuulonen et $a l^{3}$ reported that high prelaser pressure was a predictor of failure in glaucoma patients on medication. This was supported by our findings. Some reported observations indicate that, as in our material, the severity of the disease may be of importance. In a long-term study Wise ${ }^{2}$ found that eyes with a cup-disc ratio $\geq 0.9$ had a surgery rate of $51 \%$ compared with $16 \%$ in eyes with less advanced damage of the optic nerve head. Tuulonen et al noted that primary LTP gave better results than laser treatment in eyes already on medication..$^{23}$ In their patients eyes treated with primary LTP were in an earlier stage of the disease than eyes already on medication. This may indirectly suggest that the severity of the disease is also of importance.

In our opinion LTP should be considered as an alternative to medication for the initial treatment of glaucoma. The probability of success after four years is 0.50 even in a group of eyes with a mean prelaser IOP of $35.2 \mathrm{mmHg}$. There is a high failure rate during the first month after LTP, presumably owing to a group of eyes not responding to laser treatment. Given success one month after treatment, the probability of success increases to 0.63 after four years. The treatment is easy to perform, the complication rate is low, there are no compliance problems as with medication, and the treatment is not expensive. All stages of the disease respond to treatment. On the other hand the severity of the visual field defects and high prelaser IOP are negative prognostic factors.

1 Wise JB. Long-term control of adult open angle glaucoma by argon laser treatment. Ophthalmology 1981; 88: 197-202.

2 Wise JB. Ten year results of laser trabeculoplasty. Does the laser avoid glaucoma surgery or merely defer it? Eye 1987; 1 : 45-50.

3 Ticho U, Nesher R. Laser trabeculoplasty in glaucoma. Arch Ophthalmol 1989; 107: 844-6.

4 Rosenthal AR, Chaudhuri PR, Chiapella AP. Laser trabeculoplasty primary therapy in open-angle glaucoma. Arch .

5 Thomas JV, El-Mofty A, Hamdy EE, Simmons RJ. Argon laser trabeculoplasty as initial therapy for glaucoma. Arch Ophthalmol 1984; 102: 702-3.

6 Tuulonen A. Laser trabeculoplasty as primary therapy in chronic open angle glaucoma. Acta Ophthalmol (Kbh) 1984; 62: $150-5$.

7 Tuulonen A, Koponen J, Alanko HI, Airaksinen PJ. Laser trabeculoplasty versus medication treatment as primary therapy for glaucoma. Acta Ophthalmol (Kbh) 1989; 67: 275-80.

8 Migdal C, Hitchings R. Control of chronic simple glaucoma with primary medical, surgical and laser treatment. Trans Ophthalmol Soc UK 1986; 105: 653-6.

9 Tuulonen A, Niva A-K, Alanko HI. A controlled five-year follow-up study of laser trabeculoplasty as primary therapy

10 Glaucoma Laser Trial Research Group. The glaucoma laser trial. Acute effects of argon laser trabeculoplasty on intratrial. Acute effects of argon laser trabeculoplasty on

11 Elsås T. Primary lasertrabeculoplasty: a comparison of 50 spots in $180^{\circ}$ and 100 spots in $360^{\circ}$ of the trabecular meshwork. Acta Ophthalmol (Kbh) 1987; 65: 323-5.

12 Elsås T, Johnsen H, Brevik TA. The immediate pressure response to primary laser trabeculoplasty - a comparison of one and two-stage treatment. Acta Ophthalmol (Kbh) 1989; 67: 664-8.

13 Schwartz B. Cupping and pallor of the optic disc. Arch Ophthalmol 1973; 89: 272-7.

14 Kidd MN, O'Connor M. Progression of field loss after trabeculectomy: a five-year follow-up. $\mathrm{Br} \mathrm{F}$ Ophthalmol 1985; 69: 827-31.

15 Aulhorn E. Visual field defects in chronic glaucoma. In: Heilman K, Richardson KT, eds. Glaucoma: conceptions of a Heilman K, Richardson KT, eds. Glaucoma:

16 Laless JF. Statistical models and methods for lifetime data. New York: Wiley, 1982: 343-400.

17 Kaplan EL, Meier P. Nonparametric estimation from incomplete observations. $\mathcal{F}$ Am Stat Assoc 1958; 53: 457-81.

18 Cox DR. Regression models and life tables. $\mathcal{F} R$ Stat Soc $B$ 1972; 34: 187-220.

19 Wilkinson L. SYSTAT: The system for statistics. Evanston: SYSTAT Inc 1988.

20 Gaasterland DE. A review of surgical alternatives to medical therapy for glaucoma. F Natl Med Assoc 1988; 80: 721-3.

21 Shingleton BJ, Richter CU, Bellows AR, Hutchinson BT Glynn RJ. Long-term efficacy of argon laser trabeculoplasty. Glynn RJ. Long-term efficacy of a
Ophthalmology 1987; 94: 1513-8.

22 Schwartz AL, Kopelman J. Four-year experience with argon laser trabecular surgery in uncontrolled open-angle glaucoma. Ophthalmology 1983; 90: 771-80.

23 Tuulonen A, Airaksinen PJ, Kuulasmaa K. Factors influencing the outcome of laser trabeculoplasty. Am f Ophthalmol 1985; 99: 388-91.

24 Bergeå B. Intraocular pressure reduction after argon laser trabeculoplasty in open-angle glaucoma. Acta Ophthalmol $(K b h)$ 1986; 64: 401-6.

25 Safran MJ, Robin AL, Pollack IP. Argon laser trabeculoplasty in younger patients with primary open-angle glaucoma. Am in Ophthalmol 1984; 97: 292-5.

26 Zborowski L, Ritch R, Podos SM, Boas R. Prognostic features in laser trabeculoplasty. Acta Ophthalmol (Kbh) 1984; 62: in laser.

27 Grinich NP, Van Buskirk EM, Samples JR. Three-year efficacy of argon laser trabeculoplasty. Ophthalmology 1987; 94: 858-61.

28 Traverso CE, Spaeth GL, Starita RJ, Fellman RL, Greenidge $\mathrm{KC}$, Poryzees E. Factors affecting the result of argon laser trabeculoplasty in open-angle glaucoma. Ophthalmic Surg 1986; 17 : 544-9.

29 Schwartz AL, Love DC, Schwartz MA. Long-term follow-up of argon laser trabeculoplasty for uncontrolled open-angle glaucoma. Arch Ophthalmol 1985; 103: 1482-4. 